DOSSIE "Didática e Formação de Professores"

\title{
Una experiencia didáctica sobre producción de imágenes y diferencia en la formación de profesores ${ }^{12} 3$
}

\section{A didactic experience about the production of images and difference in teacher training}

Anelice Astrid Ribetto (i)

José Valter Pereira (ii)

(i) Universidade do Estado do Rio de Janeiro - UERJ, São Gonçalo, RJ, Brasil. https://orcid.org/00000003-1097-4880, anelatina@gmail.com

(ii) Universidade Federal Rural do Rio de Janeiro -UFRRJ, Nova Iguaçu, RJ, Brasil.

https://orcid.org/0000-0002-1765-5930,valterfile@gmail.com

Resumen:
El texto se propone una reflexión sobre el desarrollo del proyecto didáctico
"Narrar las experiencias de alteridad en Educación" experimentado en la materia
de Práctica Pedagógica de la Carrera de Pedagogía de la FFP/UERJ. El objetivo
de este proyecto fue producir un ejercicio didáctico de problematización sobre las
formas de mostrar y mirar las diferencias en educación, especialmente a partir de
fotografías producidas por los propios alumnos en la práctica pedagógica que
desarrollan en escuelas. El texto se estructura en cuatro partes: la primera presenta
el proyecto didáctico, la segunda trae consideraciones sobre la Práctica Pedagógica
como espacio didáctico de experimentación, la tercera introduce una discusión
sobre las formas de producir imágenes de la diferencia y, finalmente, exponemos y
discutimos algunas fotografías producidas por los futuros docentes.
Palabras clave: Alteridad, imágenes, práctica pedagógica, diferencias, didáctica

1 Apoyo: Fundação Carlos Chagas Filho de Amparo à Pesquisa do Estado do Rio de Janeiro (FAPERJ)

2 Preparación y revisión de textos (Español): Miriam Osuna - miriamos@terra.com.br

${ }^{3}$ Normalización bibliografica: Vera Bonilha - verabonilha@yahoo.com.br 


\title{
pro.posıções
}

http://dx.doi.org/10.1590/1980-6248-2017-0036

$e$-ISSN 1980-6248

\begin{abstract}
:
The text proposes a reflection on the development of the didactic project "Narrate the experiences of alterity in the Education" tried in the discipline of Supervised Internship of the Course of Pedagogy of the FFP / UERJ. The objective of this project was to produce a didactic exercise of problematization on the ways of showing and looking at differences in education, mainly based on photographs produced by the students themselves in the pedagogical practice they develop in schools. The text is structured in four parts: the first presents the didactic project, the second presents considerations about the Supervised Internship as didactic space of experimentation, the third introduces a discussion about the ways of producing images of difference and, finally, we expose and discuss some photographs produced by future teachers.
\end{abstract}

Keywords: alterity, images, supervised internship, difference, didactic

\section{Sobre el proyecto...}

Este texto tiene como principal antecedente otro proyecto experimental ensayado en el mismo espacio de formación en el año 2009. Este primer proyecto estaba atravesado por las palabras-concepto resistencia y potencia, por las consideraciones de Jorge Larrosa (2001) sobre experiencia y de Carlos Skliar (2005) sobre alteridad en la educación (que es) del otro a partir de la posibilidad de experimentarnos como sujetos - en la escena pedagógica priorizando la discusión de aquello que irrumpe e interrumpe como diferencia y como acontecimiento. En este sentido nos interesaba pensar las miradas del investigador, del educador y de los estudiantes desde una escena diferente de aquella que ha privilegiado históricamente la mismidad: se trataba de pensar en la resistencia y la potencia de saberes, otros saberes, creados en la cotidianeidad de la educación y las formas como las narramos.

Esta experiencia puso en el centro de la conversación la pregunta "¿en qué lengua vamos a contar aquello que nos acontece?". Pregunta inspirada en algunos otros textos de Jorge Larrosa (2006b) y que derivó en la producción de una serie de cuentos sobre las prácticas pedagógicas de los alumnos en la propia pasantía. Ya no buscábamos describir nuestras observaciones sobre una escuela - casi siempre en falta - sino narrar nuestras experiencias sobre las posibilidades de potencia de una escuela que aparece, muchas veces, como (in)visible - en la mirada del alumno - y que irrumpe como acontecimiento. En esta experiencia, algunas de las alumnas (se) narraron a través de fotografías sacadas en las escuelas de realización de la 


\section{pro.posições}

$e-I S S N$ 1980-6248

http://dx.doi.org/10.1590/1980-6248-2017-0036

pasantía. Fue a partir de esta práctica - no planeada - que el proyecto actual fue siendo pensado, pues percibimos que la mayoría de las veces las imágenes, aparentemente, sólo revelaban un saber sobre la escuela: el saber que ya se tenía. O sea, antes del encuentro con la cotidianeidad escolar, las pasantes ya sabían lo que allí encontrarían (y narrarían con palabras o imágenes), o mejor, todo lo que allí no encontrarían, pues las imágenes y las frases se referían -anticipadamente- a una escuela en falta, a una escuela incompleta, a una escuela deficiente.

Por otro lado, también como antecedente, algunos de los campos de saberes y experiencias por los que transitamos -tensa e intensamente - desde hace algunos años podrían definirse, tal vez, como espacios de estudios y trabajo con las diferencias. En estos espacios, considerados muchas veces como campos de alteridad, nos hemos enfrentado frecuentemente con la pregunta “¿quién es el otro?”, para la cual las respuestas que frecuente y rápidamente han sido dadas se refieren a cuestiones impregnadas de saberes (e imágenes) sobre los llamados otros, saberes (e imágenes) que, repetidamente nos enseñan la incompletud, la deficiencia, la anormalidad encarnada.

Esta concepción de la escuela pública y del público que la frecuenta se presenta, habitualmente, como una expresión "natural" que es dada a priori y con fuerza de discurso de verdad, lo que genera una dificultad enorme para problematizar los puntos de vista de los saberes e imágenes producidos por los alumnos pasantes. Los saberes e imágenes producidos son, generalmente, atribuidos a una "realidad" que está fuera de quien la narra. No se coloca en cuestión el ojo que mira ni los valores de la boca que dice. Podemos entender este movimiento en el marco de lo que hemos llamado, en el campo de la Educación Especial, de diferencialismo: la pobreza es del pobre, la violencia es del violentado, la deficiencia es del otro.

Considerando estos aspectos, colocándonos a contramano de estas concepciones y pensando en la posibilidad de trabajar la pasantía como laboratorio de experimentación de otras formas de narrar el encuentro con los otros, organizamos el programa para tuviera lugar en el espacio de una escuela pública. Esta institución funciona con clases regulares, clases especiales y salas de recursos multifuncionales que son las tres formas de organización de la Educación Especial, según la Política Nacional de Educación Especial en la Perspectiva de la Educación Inclusiva (MEC, 2008). De esta forma, nuestros alumnos tendrían la posibilidad de 


\section{pro.posıções}

$e-I S S N$ 1980-6248

http://dx.doi.org/10.1590/1980-6248-2017-0036

realizar la pasantía en espacios educacionales llamados inclusivos, habitualmente considerados espacios de la educación especial.

Aunque este ensayo no tenga como objetivo discutir los diferentes paradigmas del campo de la Educación Especial ni tampoco la tensión existente en la enseñanza regular por la re-significación de la propia modalidad ya no como escuela sino como modalidad transversal de la enseñanza brasileña, es necesario decir que este es un campo en tensión y que

una frontera separa de modo muy nítido aquellas miradas que continúan pensando que el problema está en la "anormalidad"; de aquellas que hacen lo contrario, es decir, que consideran la "normalidad" como el problema. Las primeras -sólo en apariencia más científicas, más académicas- siguen obsesivas por aquello que es pensado y producido como "anormal"; vigilando cada uno de los desvíos, describiendo cada detalle de lo patológico, cada vestigio de anormalidad y sospechando de toda deficiencia. Este tipo de miradas no es útil para la educación especial ni para la educación en general: lo "anormalizan" todo y a todos. Las otras miradas -tal vez menos vigilantes, pero también menos pretenciosas- tratan de invertir la lógica y el poder de la normalidad, haciendo de esto último, de lo normal, el problema en cuestión [destacado en el original]. (Skliar, 2005, p.15)

Es en esta última perspectiva que nuestro trabajo pretende situarse, intentando provocar(nos) una desnaturalización del acto de mirar y una pregunta continua sobre la producción de imágenes cotidianas de alteridad, en la relación con el otro.

En este sentido, la primera intención de trabajar con esta producción como centro del estudio de esta disciplina fue sacar fotos - en la pasantía - de aquello que interrumpa nuestra tranquilidad de mirar haciéndonos ver (pensar, sentir) cosas que hasta entonces no habíamos visto (pensado, sentido), o sea, la producción de imágenes como ejercicio de alteridad... ¿Por qué? Tal vez porque tengamos la sensación, junto con Larrosa (2006a), de que

todo lo que vemos no parece ser otra cosa que el lugar sobre el cual proyectamos nuestra opinión, nuestro saber y nuestro poder, nuestra arrogancia, nuestras palabras y nuestras ideas, nuestras conclusiones. Es como si sólo fuésemos capaces de miradas concluyentes, de imágenes concluyentes. Es como si todo se nos diese a ver cubierto de explicaciones. (p.27)

Para ello invitamos a este desafío a autores como los ya citados: Carlos Skliar, que nos posibilita pensar conceptos como alteridad y diferencia y también discutir la producción de la normalidad y de la anormalidad y desplazar este debate hacia la creación de imágenes de los otros (la mayoría de las veces, anormalizados...); Nuria Pérez de Lara (2009) y Pérez de Lara y Contreras (2010) en esta misma perspectiva, ayuda a discutir quiénes son esos otros de la 


\section{pro.posıções}

$e-I S S N$ 1980-6248

http://dx.doi.org/10.1590/1980-6248-2017-0036

educación; Jorge Larrosa (2001), trayendo nuevamente la palabra experiencia para preguntarnos si algo todavía nos pasa en los espacios educativos, si algo todavía puede pasarnos cuando miramos la escena pedagógica en la pasantía, si algo todavía nos modifica al producir imágenes no esperadas; Walter Benjamin (1994) que nos ayuda a dar densidad a la relación entre experiencia y narrativa; Manoel de Barros (2000), que con su poesía nos permite pensar si es posible sacar fotos de aquello que irrumpe e interrumpe, sacar fotos del acontecimiento, pues es "difícil sacar fotos del silencio", aunque, mientras tanto, podemos intentar... Nos interesa

multiplicar las formas de mirar, multiplicar las posibilidades de todo aquello que las imágenes producen. No se trata de pensar con qué imágenes trabajo, qué imágenes acompañan contenidos o qué imágenes deberían ser presentadas, sino, tal vez, se trata de las formas de mirar, de los modos en que al mirar esas imágenes producimos algún tipo de sensibilidad, memoria y pensamiento. (Skliar, 2009, p.27)

Las lecturas y conversaciones se dieron durante nuestros encuentros en la facultad, así como la proyección y debate de películas como Janela da alma y Só dez.por cento é mentira. A partir de estos encuentros, organizamos nuestra ida a la escuela y, en dúos, frecuentamos diferentes espacios de la institución. Estos encuentros están narrados, principalmente a través de imágenes y expuestos en los encuentros en la facultad, formando así una gran mezcla de narrativas, metáforas e imágenes. Finalmente, una de las actividades organizadas dentro de este contexto formativo fue el taller "Sacar fotos de lo (in)visible".

A continuación presentaremos algunas cuestiones que se desarrollan a partir de estos encuentros, lecturas y conversaciones: una contextualización del espacio-tiempo de formación en el cual la experiencia sucedió: la pasantía; algunas consideraciones iniciales sobre las formas de mostrar, hacer ver y dar a ver las diferencias...Y, finalmente, algunas producciones imagéticas, narrativas de los alumnos participantes de esta experiencia, reunidas bajo el título de "Sacar fotos de lo (in)visible", presentadas en un juego de tres escenas:

Lo (in)visible presente...

Ver como si fuese la primera vez...

Lo normal y lo anormal... 


\section{pro.posições}

$e-I S S N$ 1980-6248

http://dx.doi.org/10.1590/1980-6248-2017-0036

\section{La pasantía como espacio de experimentación...}

La lógica hegemónica de las carreras de formación de profesores durante buena parte del siglo XX se fundamentó en la concepción epistemológica de la racionalidad técnica. En esta concepción que pone la teoría de un lado y la práctica de otro, se configura una relación de subordinación de las disciplinas pedagógicas - consideradas disciplinas prácticas, en detrimento de las teóricas - consideradas disciplinas científicas. En esta misma lógica, fueron siendo definidos los currículos de los cursos de profesorado hasta la vigencia de la Ley Brasileña de Directrices y Bases de la Educación Nacional, Ley n. 9.394 de 1996 (Lei BR 1996), como una disciplina de complementación.

En el contexto de la producción de discusiones resultantes de los movimientos de redemocratización en Brasil, la cuestión teórico-práctica de las disciplinas de Práctica Pedagógica con Pasantía se tornó, segundo Candau y Lellis (1999), objeto de estudio y de proyectos de diferentes autores que proponen, bajo diferentes formas, la unidad entre teoría y práctica. Estas autoras denuncian que las pasantías eran organizadas en función de actividades programas a priori, sin que hayan surgido de las discusiones entre educador-educando, en la cotidianeidad de la clase, de la escuela y de la comunidad. Así, el conocimiento de la realidad escolar a través de las pasantías no favorecía el pensar sobre una práctica creativa y tampoco sobre una formación focalizada en la experimentación de este proceso.

En este modelo está implícita una marca del paradigma moderno que instituyó el conocimiento científico como conocimiento universal y acabado del mundo. El espacio de producción de este saber -teórico - sería la universidad. Planteándolo en este contexto, entenderemos por qué fue asumido - en una perspectiva tecnicista e instrumental- como la instancia a través de la cual los saberes teóricos serían aplicados en la práctica. El espacio de producción de prácticas -consideradas representaciones de creencias, tradiciones, preconceptos y sentido común- sería la escuela. Así, uno de los efectos producidos fue el entendimiento de la pasantía como un momento de aplicación de teorías y no de implicación práctica-teoría-práctica.

A contramano de esta lógica e intentando ofrecer otra forma de aproximación a esta instancia de formación, algunos movimientos vienen planteándose, principalmente aquellos que se atreven a pensar la formación y la educación en sí como experiencia. Es en este movimiento que los proyectos que estamos presentando se reconocen como tales, lo que 


\section{pro.posıções}

e-ISSN 1980-6248

http://dx.doi.org/10.1590/1980-6248-2017-0036

significa empezar a pensar cómo se da nuestra aproximación a los espacios en los que la práctica de pasantía sucede: las escuelas.

Lo que hemos visto a lo largo de estas experiencias es una recurrente práctica discursiva y una mirada repetitiva que se empeña en nombrar rápida y casi que automáticamente estos espacios como espacios de falta, espacios donde nada pasa o lo que pasa tiene que ver con una práctica considerada limitada, incompleta, inapropiada y de calidad dudosa. Antes, inclusive, de producirse el encuentro entre nosotros - alumnos y profesores de la universidad y de las escuelas - ya está dicho, ya es sabido aquello que vamos a encontrar y hasta las teorías que irán a fundamentar nuestro decir faltoso. Entendemos que este proceso invalida la posibilidad de que alguna cosa nos pase, nos acontezca en este encuentro, en la pasantía. Si ya sabemos lo que vamos a encontrar, la pasantía se transforma únicamente un trámite burocrático de producción de informes que nada más tienen que ser firmados y legitimados al final del período lectivo.

Finalmente, pensamos que hacer la pasantía puede ser una experiencia de extrañamiento $\mathrm{y}$, como tal, puede ser también la experiencia de relación con este extrañamiento. Así, lo fundamental "no son nuestras habilidades como recolectores de datos ...sino aquello que nos nutre y nos prepara para vivir la experiencia y para preguntar sobre las cuestiones pedagógicas" (Pérez de Lara \& Contreras, 2010, p.68). Lo que nos interesa en esta propuesta es cuestionarnos la mirada acostumbrada que sabe con anticipación aquello que irá a ver, entendiendo que

Hay cientos de explicaciones acerca de cómo se construye la mirada pedagógica y quizás sea necesario hacer mención a la tradición de entender la formación y el saber como posición de desigualdad (desigualdad de saberes, de edades, de experiencias, de funciones). Si bien la mirada ofrece una dualidad compuesta por focos y por bordes poco explorados, sabemos que en las instituciones educativas se toman decisiones a diario producto de la naturalización de la mirada. Más allá del lenguaje técnico y especializado, más allá de los legajos e historiales, más allá de las evaluaciones y diagnósticos, incluso más allá de las relaciones puntuales al interior de las aulas, notamos que ciertas decisiones acerca de quién podrá o no podrá aprender, quién podrá o no podrá incluirse, quién podrá o no podrá "tener" [destacado en el original] futuro, dependen mucho más de un juego (muy serio, muy grave) de miradas. Miradas que tienen que ver con el poder, es cierto, pero también con la posición desde la que parten, del lugar donde se forman y de los sujetos a los que van destinadas. (Skliar, 2009, p.31) 


\title{
pro.posições
}

$e-I S S N$ 1980-6248

http://dx.doi.org/10.1590/1980-6248-2017-0036

Por eso nos parece necesario repensar cómo han sido producidos esos relatos faltosos recreados por una mirada arrogantemente tecnicista con pretensiones de saberse neutra, objetiva y, fundamentalmente, de qué forma, con qué imágenes los otros (de la educación) han sido presentados y las formas como los hemos mirado.

\section{Las formas de narrar, mostrar, hacer ver y dar a ver las diferencias...}

\author{
Si lo que hay ante una imagen es exposición, \\ la mirada es claramente una posición, un punto de partida, \\ una dimensión inaugural, \\ posee un valor de principio: revela la posición de quién mira, \\ desde dónde mira, qué altura se atribuye al mirar, \\ en cuál posición deja o ubica a quien es mirado. \\ No se trata tanto de mencionar su dispositivo biológico \\ ni el aparataje cultural que lo gobierna, \\ sino los modos de posicionarse al mirar y al mirarse. \\ (Skliar, 2009, p.33)
}

Entonces, narrativas, miradas... imágenes... modos de posicionarse al mirar y mirar(se) en relación a los otros. Pero, ¿quiénes son los otros? ¿Cuáles son las respuestas que históricamente han sido dadas para esta cuestión? O mejor, ¿desde qué lugares de saber y poder han sido narrados y presentados esos otros de la educación?

En primer lugar, parece necesario retomar una cuestión enunciada al principio de este texto y que se refiere a la forma en que entendemos necesita ser pensada la cuestión de la diferencia, muchas veces identificada como anormalidad. Nuestra apuesta es un esfuerzo exactamente para preguntarnos ya no por la anormalidad y por quien la encarna -entre ellos, los deficientes- sino, radicalizar nuestra pregunta por la normalidad. Cuestionar la normalidad...

Entendemos con Skliar y Téllez (2008) que

La educación en general no se demuestra preocupada con las diferencias sino con aquello que podríamos denominar como una cierta obsesión por los "diferentes". Los "diferentes" obedecen a una construcción, una invención, son un reflejo de un largo proceso que podríamos llamar de "diferencialismo", esto es, una actitud -sin dudas racista- de separación y de disminución, el empequeñecimiento de algunos trazos, de algunas marcas, de identidades en relación a la vasta generalidad de diferencias. Las diferencias no pueden ser presentadas ni descriptas en términos de mejor o peor, bien o mal, superior o inferior, positivas o negativas, etc. son de un modo crucial, álgido, simplemente diferencias. ...De hecho, en qué son o cómo son las diferencias sino en cómo se inventa y reinventa, cotidianamente a los "diferentes" [destacado en el original]. (pp. 10-11) 


\section{pro.posições}

$e-I S S N$ 1980-6248

http://dx.doi.org/10.1590/1980-6248-2017-0036

Repetimos, ¿cómo se inventan y se reinventan, cotidianamente los “diferentes"? Para entender mejor esta invención, esta reinvención de las anormalidades y los lugares que históricamente fueron producidos para ella a partir de narrativas e imágenes es necesario instaurar la pregunta sobre la normalidad. Al poner nuestra pregunta en la construcción de la normalidad, en cierta forma, cambiamos el foco, la figura y el fondo, pues, durante mucho tiempo las dichas anormalidades fueron consideradas como un problema individual, lo máximo, familiar. Nosotros planteamos la pregunta sobre la relación: cuáles son las relaciones históricas, políticas, culturales que necesitaron producir otros para reforzar lo Mismo y con qué imágenes han sido narrados esos otros.

La normalidad y sus muchas expresiones son tenidas como verdad, certeza, como dato natural, como imagen de realidad, bien como el propio concepto de aquello que es "natural", sin embargo, son sólo construcciones históricas en torno de las cuales una serie de discursos, de imágenes, de poderes, y toda una serie de saberes se construyó y sedimentó. Así

los deficientes construidos como otros de la normalidad, pero necesarios a esta normalidad, suelen ser pensados en otro plano, como no completamente humanos, como necesitados de protección y tutela. No hablan por si, son objetos de habla, sujetos de un discurso que no les pertenece. Las construcciones discursivas sobre ellos parten del presupuesto de que ellos no son, ni pueden ser tan humanos como el nosotros; de que son seres humanos incompletos, torcidos o desviados, proyectos inconclusos, un devenir más que un ser. Sus existencias se resumen a su deficiencia, a su cuerpo - deficiente, disfuncional, no adaptado, grotesco o, tan sólo, diferente - tomado como simple dato biológico, desvinculado de toda producción sociohistórica. (Climaço, 2010, p.11)

Una de las inversiones más fuertes de ese proyecto se da exactamente en la posibilidad de - a través de la pasantía - crear un espacio de pregunta y cuestionamiento sobre esos saberes, sobre esas narrativas, sobre esas imágenes que muestran un otro anormal y que han sido naturalizadas a tal punto que una de las alumnas de la disciplina expresó, inmediatamente después de la primera ida a la escuela, su sorpresa al percibir el lugar como "un lugar limpio, arreglado, con personas que se manifestaban felices y sobre todo bien comportadas... yo pensé que esos alumnos iban a saltar encima de mí (como fieras)" ¿A qué aprendizaje obedecería esta argumentación? Argumentación de una aluna que está en el último año de la carrera de Pedagogía de una Facultad de Formación de Profesores...

Por eso nos parece mucho más oportuno empezar por la experiencia, por aquello que nos pasa en el encuentro con el otro, en las relaciones de alteridad, en vez de empezar por el 


\section{pro.posições}

$e-I S S N$ 1980-6248

http://dx.doi.org/10.1590/1980-6248-2017-0036

camino inverso: que alguien - el profesor - nos diga desde el lugar del saber y del poder lo que son los otros. Apostar en la experiencia significa que tal vez esta pregunta no tenga una respuesta correcta, ni programada, sino que continúe pura pregunta. Porque, en principio, "son aquellos y aquellas alumnas que con sus modos de ser, de moverse, de mirar, de sentir, de oír, de atender, de expresarse enfrentan a la pedagogía, porque hacen temblar sus principios, con su simple presencia en las aulas” (Pérez de Lara, 2009, p.47).

Asimismo nos preguntamos con la autora: ¿qué producen en mí sus presencias? ¿Qué preguntas sus miradas evocan en mí? ¿Por qué parece que es hoy que necesitamos pensar sobre la relación con esos otros si ellos siempre han estado ahí? Y dice Nuria Pérez de Lara (2009,) “¿qué es lo que siento que cambia en mí la experiencia de la relación con el Otro, o sea, mi experiencia de la relación con niños y niñas singulares para quienes esta palabra 'Otro' reduce todas sus diferencias y singularidades a la indiferencia?” (p. 50).

El hecho de cambiar el punto de vista y dejar de mirar una supuesta marca, carga o falta estampada en el cuerpo y en la existencia del otro, y enfocar nuestra mirada en la relación que se establece fundamentalmente a través de la mirada de quien mira es el eje de la experiencia y, de las narrativas creadas a partir de esta.

Entendemos que la educación está vinculada a los encuentros... encuentros que son "pasionales, vividos como reconocimiento de la extrañeza en común, lo que no permite al estudiante y al profesor hablar del otro sin hablarse" (Gutiérrez, 2006, p. 167). Desde el punto de vista de la narración, la acción educativa puede ser pensada como involucramientos con experiencias. El estudiante es capaz de vivir la experiencia que le fue transmitida. En la acción educativa "narrada" se da el ejercicio de configuración-refiguración (Ricoeur, 2010, p.234), o sea, el movimiento en que profesores y estudiantes buscan la conexión de las diferentes narrativas con las historias individuales que pasan a inscribirse en un contexto más amplio, en sus tensiones.

No pretendemos que estos conceptos se transformen rápidamente en un modelo didáctico-pedagógico más a ser absorbido. Sólo pretendemos expandir las posibilidades de pensamiento y que esta apertura nos ayude a entender mejor la formación de nuestros estudiantes. Así, creemos que tal vez sea importante recuperar no sólo los conceptos que resuenan con el de narrativa, sino también las dificultades que estas resonancias sugieren. 


\section{pro.posıções}

$e-I S S N$ 1980-6248

http://dx.doi.org/10.1590/1980-6248-2017-0036

Benjamin (1994) advierte que si la narrativa se alimenta de la experiencia, la degradación de una lleva, inexorablemente, al deterioro de la otra. Así acusa, por ejemplo, a los medios de comunicación modernos y al flujo masacrante de informaciones. Informaciones que, según el autor, nos tornan más pobres de experiencia. La diferencia de la información con relación a la narración es que en toda la información es necesaria la constante verificabilidad. Además de poder verificarse objetivamente, la información debe ser siempre novedosa y luego resultar efímera. Una información antigua y perenne deja de ser interesante, mientras que las buenas historias atraviesan muchas generaciones.

¿Qué necesita el trabajo con narrativas? Creemos que la primera cuestión está en lo oído, principalmente, en la identificación de una buena historia. Benjamin alerta sobre el trabajo (y la dificultad) de la escucha. La verdadera escucha no depende solamente de una sala silenciosa y con buena acústica. La escucha pertenece a otro orden. Significa un olvido de sí para prestar atención a lo otro, al otro. La escucha carece de un vacío, una renuncia temporaria de la propia identidad que debe convertirse en fidelidad consigo mismo. "Cuanto más olvidado de sí mismo, más profundamente se impregna su memoria de lo oído" escribe Benjamin (1994, p. 18). Pero lo oído no se engaña con cualquier historia... Lo segundo, es el mirar y su relación con lo mirado. Una historia que no se yergue de la experiencia, como exigencia de la memoria, como un trabajo que involucra una trama que organiza un acontecimiento, no llega al oído, no toca, no conmueve. O no es mirado con implicación. Esto sucede cuando vamos a encontrarnos con los sujetos de nuestras investigaciones que deben responder a preguntas que se prestan más a organizar lo que queremos qua a crear condiciones para que la memoria, las experiencias vividas por nuestros interlocutores y que ellos nos lleven por lugares insondables, que nos ayuden a organizarnos en el tiempo. Que nos propongan nuevas formas de mirar. Y de ver. Muchas veces las entrevistas trabajan a favor de una organización, de un control para que no corramos el riesgo de oír lo que no queremos oír, de que los relatos nos lleven para mundos que no conocemos y ni controlamos, desorientando aquello que ya sabíamos de antemano. El control de la entrevista, en esta perspectiva, sugiere a nuestros entrevistados que ellos deben concentrase para adivinar aquello que queremos saber. Quedan a merced de lo que queremos, olvidándose de sus historias, relegando sus experiencias a lo que no tendría valor.

Nuria Pérez de Lara y José Contreras Domínguez (2010), tratan detalladamente los movimientos producidos por un grupo de autores interesados en la educación como 


\section{pro.posıções}

e-ISSN 1980-6248

http://dx.doi.org/10.1590/1980-6248-2017-0036

experiencia. Los autores dicen que trabajar con la experiencia requiere estar a la escucha, en espera... saber que no siempre la experiencia se deja pensar bien, se deja descifrar, no existiendo modo de saturar sus sentidos y sabiendo que la pregunta por el sentido de la experiencia es también una pregunta por el sin-sentido (Pérez de Lara \& Contreras, 2010, p.36).

Entonces, ¿De qué modo podemos intentar aproximarnos a las experiencias y a los sentidos de las experiencias en la educación? De lo que se trata no es sólo de producir investigaciones, estudios, escritos sobre los relatos de los otros, sobre las narrativas de los otros, sobre las formas que miramos o damos a mirar a los otros. Se así fuese podríamos "estar considerando los relatos de las personas sólo como datos que tratamos, analizamos, categorizamos y convertimos en objetos de conocimiento" (Pérez de Lara \& Contreras, 2010, p.81), se trata de estar disponibles para el encuentro con el otro.

\section{Tres experiencias, tres escenas}

Difícil fotografar o silêncio.

Entretanto tentei. Eu conto:

Madrugada a minha aldeia estava morta. Não se ouvia um barulho, ninguém passava entre as casas. Eu estava saindo de una festa.

Eram quase quatro da manhã. Ia o silêncio pela rua carregando um bêbado.

Preparei minha máquina.

O silêncio era um carregador?

Estava carregando o bêbado.

Fotografei este carregador.

(Manoel de Barros, 2000, p. 15)

La primera pregunta que se nos ocurrió cuando ofrecimos un taller de fotografía a los/las alumnos(as) de la pasantía fue: ¿cómo trabajar las diferentes y complejas cuestiones de la fotografía trazando un paralelo con las cuestiones propuestas por la pasantía y con las cuestiones que nos desafían en la investigación a partir de las implicaciones entre visión y conocimiento? Y dentro de la misma preocupación con el taller: ¿cómo llamar la atención sobre la "ceguera" producida por las imágenes "naturales", banalizadas y "banalizables" del mundo? A partir de estas cuestiones surgen otras, como la implicación de nuestras 


\section{pro.posıções}

$e-I S S N$ 1980-6248

http://dx.doi.org/10.1590/1980-6248-2017-0036

limitaciones de ver el mundo, de nuestras certezas. Implicación de nuestra fe en aquello que sostenemos como exclusivamente del otro, ya que la imagen lo tiene como referente. O sea, nuestra fe en que la imagen que producimos tiene un solo lado: el lado externo del ojo, exterior a nuestro cuerpo. Ojo que ve, como suponen algunos, y reproduce únicamente aquello que se ofrece al visor de la cámara. Se piensa que sacamos fotos de lo que existe tal cual se presenta a los ojos de todos.

La fotografía, más que componer modelos geométricos, pone en marcha los medios visuales que pasan a imponerse, también, como modelos cognitivos y perceptivos de una época, de un determinado grupo social, de una determinada cultura, de una determinada manera de ver el mundo. Depende no sólo de un aparato mecánico y un modelo (el referente), sino de aquello que preexiste al acto de sacar fotos, o sea, aquello que se refiere a la subjetividad del fotógrafo y que va a incidir sobre sus decisiones sobre qué mostrar y/o qué esconder. Ningún acto de sacar fotos puede ser considerado un acto banal, sin referentes, aislado en sí mismo. Este acto revela la reacción del fotógrafo a lo que se le presenta en una determinada circunstancia, en un determinado tiempo-espacio. Lo que se presenta para ser traducido, para ser registrado, para ser "revelado", para ser re-creado. ¿Cómo reaccionamos a estos momentos? ¿De qué se componen nuestras elecciones? ¿Qué escenas construimos y qué modelos de sociedad estas se prestan a mostrar y a qué visiones de mundo contribuyen a reforzar o borrar?

El taller no pretendía ser una clase expositiva con textos, lecturas y debates sobre lo que fue leído. Pretendíamos experimentar algunos ejercicios donde cada uno/una pudiese exponer(se) al mostrar lo que podían "ver", al mostrar los límites de la mirada y las dificultades de ejercitar otras posiciones para el cuerpo, otras posiciones frente a lo que se presenta, a los acontecimientos.

Empezamos mostrando algunas imágenes e intentando relacionar algunos conceptos y algunas técnicas fotográficas clásicas a los problemas que están siendo trabajados en la pasantía. Propusimos, de entrada, la problematización del "punto de vista", el lugar donde cada uno/una se planta frente a las situaciones que se dan a ver; tanto como fotógrafos, como pasantes o como investigadores.

Después propusimos un ejercicio (que podría hacerse con cámaras digitales, celulares o cualquier otro aparato de producción de imágenes): pedimos que cada uno/una saliese de la 


\section{pro.posições}

$e-I S S N$ 1980-6248

http://dx.doi.org/10.1590/1980-6248-2017-0036

sala donde estaba siendo realizado el taller y fuese a producir imágenes sobre la universidad. Y que, en el momento del "click", se piensa en la "posición" que estaban "asumiendo" frente al "tema". Esto es porque cuando nos situamos en una posición mostramos las cosas de una manera. Diferentes posiciones (diferentes puntos de vista) muestran las cosas de diferentes maneras. De esta forma, las diferentes maneras de mostrar aquello que se nos presenta, tal vez desestabilice la idea de que sólo existe una posibilidad de mostrar, una posibilidad de ver, una posibilidad de "ser". Pedimos que cada uno se "observase" sacando fotos. Observase, cuestionase y desnaturalizase los puntos de vista más cómodos. Que se moviesen (buscando, evaluando, experimentando), que se agachasen, que se subiesen a las cosas, que desestabilizasen la postura supuestamente natural del cuerpo. Imaginemos cómo deben haber reaccionado los cuerpos, pues tendemos a ver el mundo siempre en posición erecta, en la “posición” más cómoda. En el acto fotográfico (y a veces, también en la investigación, en la vida en general), muchos no suelen involucrar al cuerpo y sus condiciones de confort y padecimiento como costos de las "tomas de posición", de las tomas de decisión. El "click" puede ser pensando en su antes, por la toma de posición - que incluye la elección de los ángulos, del encuadre, etc. -, y por el momento de la compresión del dedo sobre el botón de la cámara fotográfica que es la conjugación de la toma de posición con una decisión.

Retornando de la actividad, al mostrar las fotos, pedíamos que hablasen sobre el acto de sacar fotos, intentando responder a las siguientes preguntas: ¿será que a partir de un lugar común, de una escena familiar (el lugar en que muchos conviven diariamente) es posible mostrar algo que aún no fue visto? Y, más que eso: ¿cómo mostrar de otras maneras lo que todos ya vieron y ven? ¿Cómo mostrar lo banalizado de otra forma, ofreciendo oportunidades de ampliación de las formas de ver aquel "tema"? ¿Cómo mostrar de forma que la imagen creada actúe contra la banalización de la mirada, contra la banalización de lo que se ve o, incluso, contra la disminución de la capacidad de ver?

Trabajamos también la relación entre el "punto de vista" y aquello que se quería mostrar. Insistimos en que si abdicamos de la problematización de nuestro "punto de vista", si nos conformamos ( $\mathrm{y}$ nos confortamos) en dar a ver aquello que todos ya saben y ya vieron (ya que siempre se trata del tema "narrado" de la misma manera), tal vez estemos perdiendo la oportunidad de mostrar de otras maneras las cosas que ya fueron vistas, que ya se sabe lo que

\footnotetext{
${ }^{4}$ En lenguaje fotográfico, asunto es lo que va a ser fotografiado.
} 


\section{pro.posıções}

$e-I S S N$ 1980-6248

http://dx.doi.org/10.1590/1980-6248-2017-0036

son, pues siempre son vistas a partir del mismo lugar ocupado por el fotógrafo(a). Así vamos quedándonos ciegos de tanto ver (lo mismo), diría Caetano Veloso. Asimismo, al buscar otras posibilidades de dar a ver - cuestionando nuestro punto de vista, lo que ponemos dentro del cuadro y lo que dejamos afuera, cuestionando el ángulo que adoptamos - sugerimos la posibilidad de ver algo que nos sorprenda, que no había sido visto/pensado en lo ya visto, en lo familiar que es. Pero, más que eso, sugerimos que es posible ver de muchas formas, dar a ver de muchas maneras. Tal vez estas sean las posibilidades de enfrentar la ceguera causada por la profusión de imágenes de lo mismo. Y la profusión de imágenes de lo mismo, muchas veces, privilegia puntos de vista hegemónicos, ayudando a reforzar determinados patrones de belleza, determinados estereotipos que ayudan a dar más énfasis a una llamada "normalidad", determinadas formas de ver el mundo. O sea, una "didáctica" que contribuye para la domesticación de nuestra mirada y para que reconozcamos "las formas correctas de ver" que nos hacen rechazar (o, por lo menos, generar extrañamiento negando) otros tipos de imagen, ciertas escenas, ciertas narrativas...

Tal vez lo importante de las fotografías no sea la producción de verdades, mucho menos por la supuesta representación de la realidad que ella insiste en sugerir. Sino que lo que puede importarnos tal vez sea su condición de hacernos pensar, de posibilitar la creación de otras narrativas que nos inspiren hacia otros órdenes de percepción y experiencias.

Fueron producidas muchas imágenes. Algunas de ellas se muestran a continuación. 


\section{pro.posıções}

http://dx.doi.org/10.1590/1980-6248-2017-0036

\section{Primera escena: lo (in)visible presente...}

Esta actividad - escena - fue la propuesta del taller de fotografía.

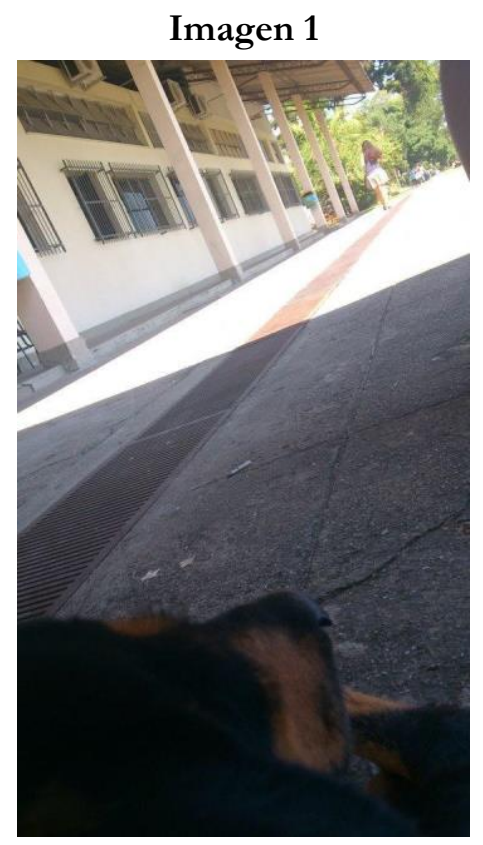

Fuente: Acervo do Projeto "Narrar las experiencias de alteridad en Educación”- Lugar: Faculdade de Formação de Professores, UERJ. São Gonçalo, RJ. Octubre de 2009

Texto Imagen 1 - escrito por una de las estudiantes: la "otra FFP": yo elegí sacar esta foto del punto de vista de los perros, al final, son cuatro años aquí y ya estoy loca para salir corriendo, ¿y ellos? ¿Cómo ven este lugar que les proporciona tanta comodidad que los hace quedar?

Esta actividad nos posibilitó pensar en algunas cuestiones; unas conseguimos trabajarlas y desdoblarlas en trabajos que fueron llevados a cabo concretamente a lo largo del cursado de la materia, pero, lo más importante fue la ampliación de las conversaciones, de las discusiones y de los movimientos potenciados por la actividad para las demás dimensiones de la vida académica, para las dimensiones de la vida. Para la actividad práctica de la materia en cuestión, a cerca de cómo trabajar en las escuelas, cómo producir imágenes sobre lo invisible, se ofreció -según los estudiantes- a partir de la idea de la implicación del cuerpo y de sus disponibilidades para moverse de la posición más cómoda, la posibilidad de cuestionar posiciones "naturales" y buscar otras posibilidades de ver y de dar a ver. Ciertamente que no debe ser así la visión del perro de la fotografía, pero, al menos, podemos pensar en um espacio visto (y habitado) desde otro ángulo, desde otro punto de vista. Fue posible, entonces, experimentar las disponibilidades y las indisponibilidades de los cuerpos, considerando 


\section{pro.posıções}

http://dx.doi.org/10.1590/1980-6248-2017-0036

$e$-ISSN 1980-6248

también las formas como nos preparamos para movernos en los espacios que habitamos, por ejemplo, la escuela.

Fue posible pensar sobre la naturalización y normalización de determinadas posturas y posiciones, sobre los lugares desde donde nos paramos para ver el mundo, casi siempre, desde la misma altura y posición, a partir de puntos de vista que la mayoría de las veces nos llevan a ver lo ya visto, lo que ya sabemos ver: nos llevan al conocimiento como reconocimiento.

Imagen 2

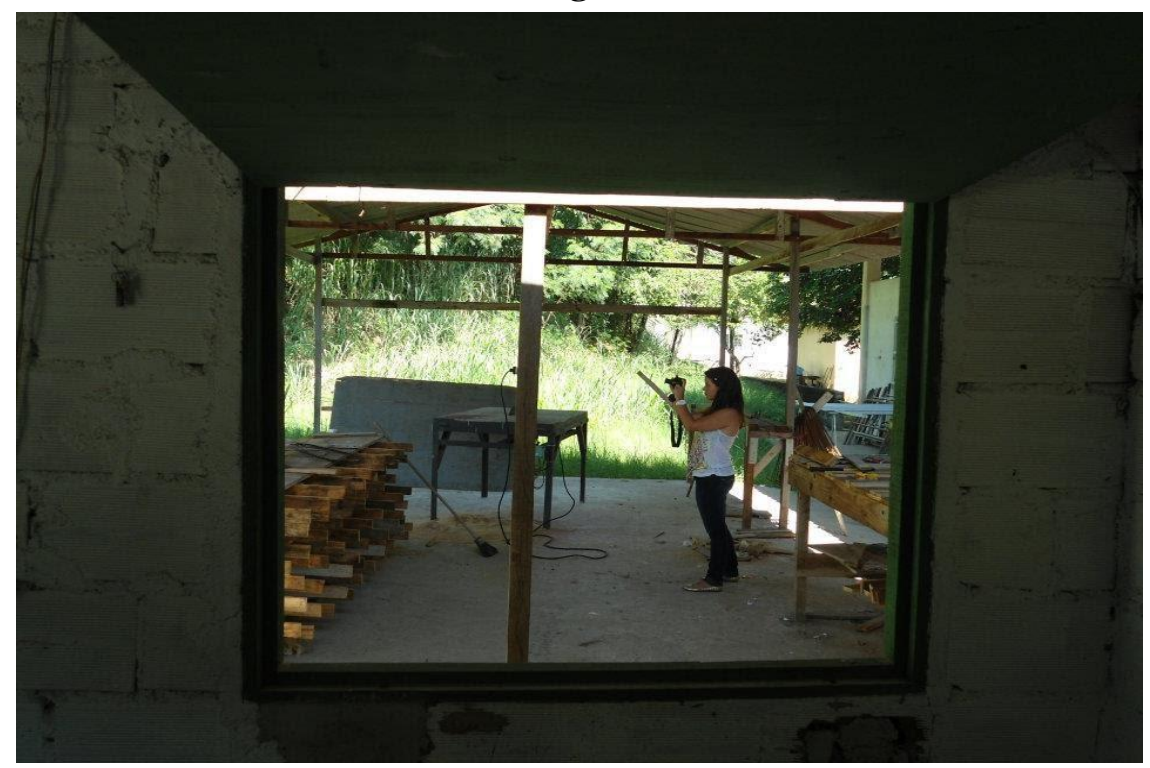

Fuente: Acervo do Projeto "Narrar las experiencias de alteridad en Educación”- Lugar: Faculdade de Formação de Professores, UERJ. São Gonçalo, RJ. Octubre de 2009

Texto Imagen 2 - : Lo invisible de la facultad en lo visible...escrito por una de las estudiantes: "la verdad, yo quería sacar fotos de una plantación de quiabos ${ }^{5}$ que hay dentro de la obra de la facultad... una facultad que no vemos habitualmente... La fotografía es la fotografía de alguien sacando fotos de los quiabos: en la imagen lo invisible -los quiabos están presentes".

Tal vez podríamos aprovechar esta foto, como hicimos en la clase donde ésta se originó, para pensar sobre algunas condiciones de la imagen, principalmente considerando el estatuto de la percepción como posibilidad y demanda de actuar y de moverse, como diría Henri Bergson (1990), percibir es actuar virtualmente sobre algo. Los elementos que constituyen la imagen -miradas, manos indicando una dirección, líneas que cortan una escenanos orientan en el paseo sobre la imagen producida. Por lo tanto, mirar implica actuar. En la

${ }^{5} \mathrm{~N}$. de T.: quiabo es una verdura alargada, pequeña, de color verde y origen africano con la que se preparan diversos platos tradicionales en Brasil. 


\section{pro.posıções}

$e-I S S N$ 1980-6248

http://dx.doi.org/10.1590/1980-6248-2017-0036

fotografía que la estudiante produce, ella intenta usar la ventana como un marco. Dentro del marco, nuestra mirada, repara en otra fotógrafa y, ésta, nos desvía para la izquierda, para intentar ver lo que su cámara ve. Una fotografía que se escapa a otra imagen, hecha en curva, con lo que no está presente, o mejor dicho, nos indica el misterio (aunque en la leyenda de la foto la estudiante afirme que intentaba fotografiar a la fotógrafa de la foto). La foto nos demanda un acto: nos lleva fuera de ella, fuera del campo visto, haciéndonos preguntar sobre el punto donde interrumpiremos nuestro paseo y sobre cómo podemos seguir adelante, nosotros, que miramos lo que mira una fotógrafa que mira para fuera del cuadro.

\section{Segunda escena: ver como si fuese la primera vez...}

Esta actividad fue propuesta a partir de la citada entrevista realizada a Carlos Skliar (2009) y fundamentalmente a partir de una frase:

Me gusta mucho algo que el poeta Alberto Caeiro sugirió en un breve texto: la oposición entre mirar por primera vez y conocer. Como si el hecho de conocer impidiera la posibilidad de mirar algo por primera vez. Como si conocer fuera negarse a ver. Como si conocer fuera dejarse de sorprender, abandonar la afección que nos provoca lo mirado. Para mí, "educar la mirada" [destacado en el original] tiene que ver también con educar para recuperar una mirada quizá infantil, quizá ingenua, pero para nada primitiva: una mirada de sorpresa, de implicación, de involucramiento con lo visto. ( p.35)

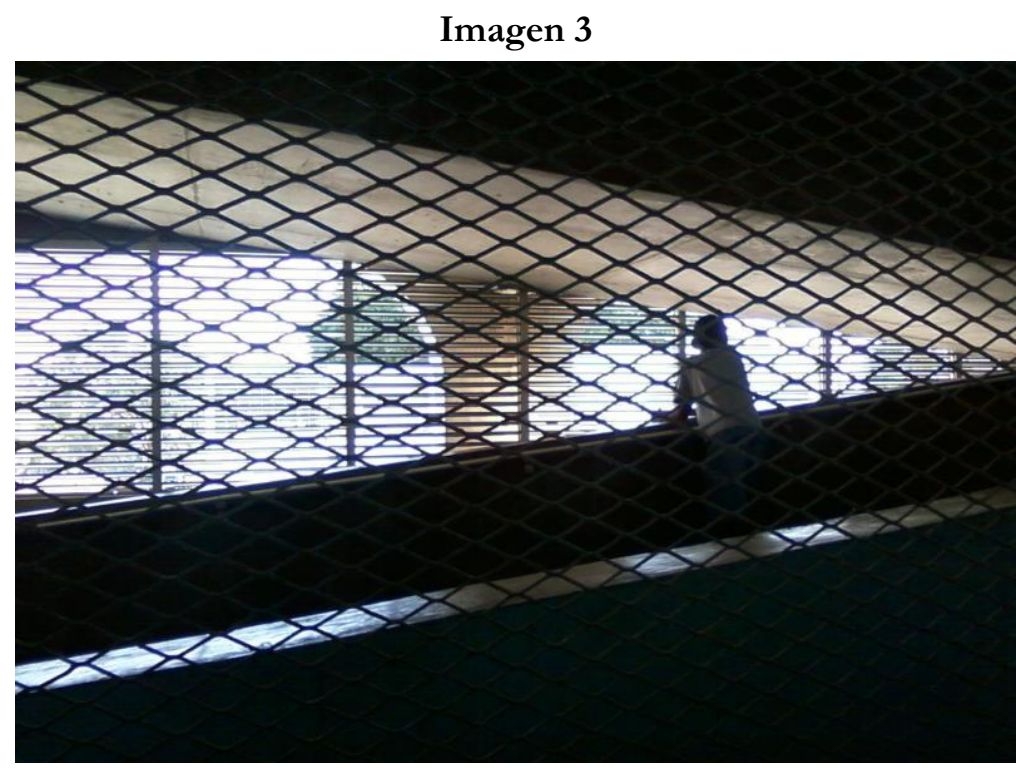

Fuente: Acervo do Projeto "Narrar las experiencias de alteridad en Educación"- Lugar: una escuela de la ciudad de São Gonçalo, RJ, Brasil. Noviembre de 2009

Texto Imagen 3 - escrito por una de las estudiantes "la escuela como yo nunca la vi..." 


\section{pro.posições}

e-ISSN 1980-6248

http://dx.doi.org/10.1590/1980-6248-2017-0036

Aquí trabajamos con las imágenes producidas por las estudiantes sobre las escuelas y lo que efectivamente cambió: la disponibilidad para movimientos del cuerpo sobre el espacio. La imágenes ya no lidian sólo con "lo que hay para ver" sino que ofrecen otras posibilidades de ver y mostrar. Se desata una provocación al ejercicio de ver y de dar a ver a partir de aquello que nos hace dudar sobre lo que ya sabíamos de las escuelas. Más que mostrar imágenes para la confirmación de la misma cosa, de lo banal, de aquello que es compartido como común por las formas anticipadas de ver, se trata de intentar una desestabilización de lo que ya no puede ser visto de otra forma.

La fotografía pretende, mucho más, preguntar a quien mira que mostrar lo que hay para ver.

En este sentido, se retoma una apuesta ética en el trabajo de los estudiantes que tiene que ver con suspender la mirada individual y prediseñada para realizar el esfuerzo de mirar las cosas como si fuera la primera vez: experimentación de una relación de alteridad con aquello que se mira, suspensión de informaciones y opiniones para dar lugar a lo que pueda venir como experiencia. En la fotografía de esta segunda escena, la estudiante no sólo busca una perspectiva otra para mirar sino que presenta una escuela que está representada en los discursos mediáticos como "la escuela de tiempo integral de Rio de Janeiro" " habitualmente ligada a una imagen de deterioro de un proyecto que de escuela pública, y la presenta de forma diferente: nadie que mira esta fotografía puede decir de antemano que es un CIEP. Experimentar ver como si fuese la primera vez que se mira.

De esta forma, abriéndose a la pasantía como espacio de experimentación la estudiante saca una foto que no se sabe lo que representa y pone en cuestión nuestros discursos y nuestras miradas sobre la escuela, sobre los profesores, sobre las prácticas pedagógicas. Nos ayuda a pensar por qué decimos lo que decimos y vemos lo que vemos pues para que alguna cosa nos pase en la pasantía necesitamos disponernos, exponernos al otro para que algo irrumpa como acontecimiento no esperado e interrumpa nuestra tranquilidad discursiva, nuestra mirada acomodada. En este sentido Gadamer (1977) dice que la experiencia significa "siempre un proceso negativo, porque supone una negación de lo que ya era sabido" (p.428).

6 Ver: https://pt.wikipedia.org/wiki/Centros_Integrados_de_Educa $\%$ C3\%A7\%C3\%A3o_P $\%$ C3\%BAblica\#/ media/File:2011-06-12_CIEP_Brizol\%C3\%A3o_172_N\%C3\%A9lson_Rodrigues.JPG

Esta es la imagen que se muestra repetitivamente sobre los Centros Integrados de Educação Pública (CIEPs) y que representa -imagen ya dada- este espacio escolar: al mostrar la fotografía ya se sabe que es un CIEP -y que, no podría ser otra cosa-. 


\section{pro.posições}

$e-I S S N$ 1980-6248

http://dx.doi.org/10.1590/1980-6248-2017-0036

Es lo vivido lo que deja su marca y provoca un efecto en nosotros. Lo vivido que deja marca se hace por un choque con lo previsto - por ser imprevisto quiebra nuestras certezas - y nos afecta de una manera no planeada, impensada: y nos transforma...

Transforma el proceso formativo pues nos hace retomar el escuchar, el mirar, el estar atentos, en el sentido benjaminiano que ya expusimos, y nos pone irreductiblemente en una relación de alteridad donde podemos sentir cosas que no queremos sentir, escuchar cosas que no pretendíamos escuchar, mirar lo que no sabíamos ver, pensar cosas que no pensábamos, ir por caminos que no habíamos planeado. Y aquello que nos llega como alteridad, aquello que tiene que ver con lo inesperado, que se presenta de improviso, sin obedecer a un plan, aquello que llega e interrumpe nuestra escucha tranquila... nuestra forma de mirar acomodada... aquello es la experiencia... la carne de la narrativa... la vida hecha relato de aquello que nos pasa, de aquello que se padece, en el sentido de la pasión como aquello que se padece: "la escuela que nunca vi" dice una alumna que frecuenta esa escuela semanalmente.

\section{Tercera escena: lo normal y lo anormal...}

La actividad fue pensada para problematizar, o mejor, preguntarnos sobre la construcción de la anormalidad a partir de la categoría de normalidad y como posibilidad de otra mirada para esta creación. Tal vez porque

la educación especial podría ser pensada como un discurso y una práctica que torna problemática e incluso insostenible —y más bien imposible— la idea de lo "normal" corporal, lo "normal" de la lengua, lo "normal" del aprendizaje, lo normal" de la sexualidad, lo "normal" del comportamiento, etc., acercándose de ese modo a otras líneas de estudio en educación, como lo son los estudios de género, los Estudios Culturales, el posestructuralismo, la filosofía de la diferencia. Si aquello que llamamos de educación especial no sirve para poner en tela de juicio "la norma", "lo normal", "la normalidad", pues entonces no tiene razón de ser ni mayor sentido su sobrevivencia [destacado en el original]. (Skliar, 2005, p.41) 


\section{pro.posıções}

$e$-ISSN 1980-6248

http://dx.doi.org/10.1590/1980-6248-2017-0036

\section{Imagen 4}

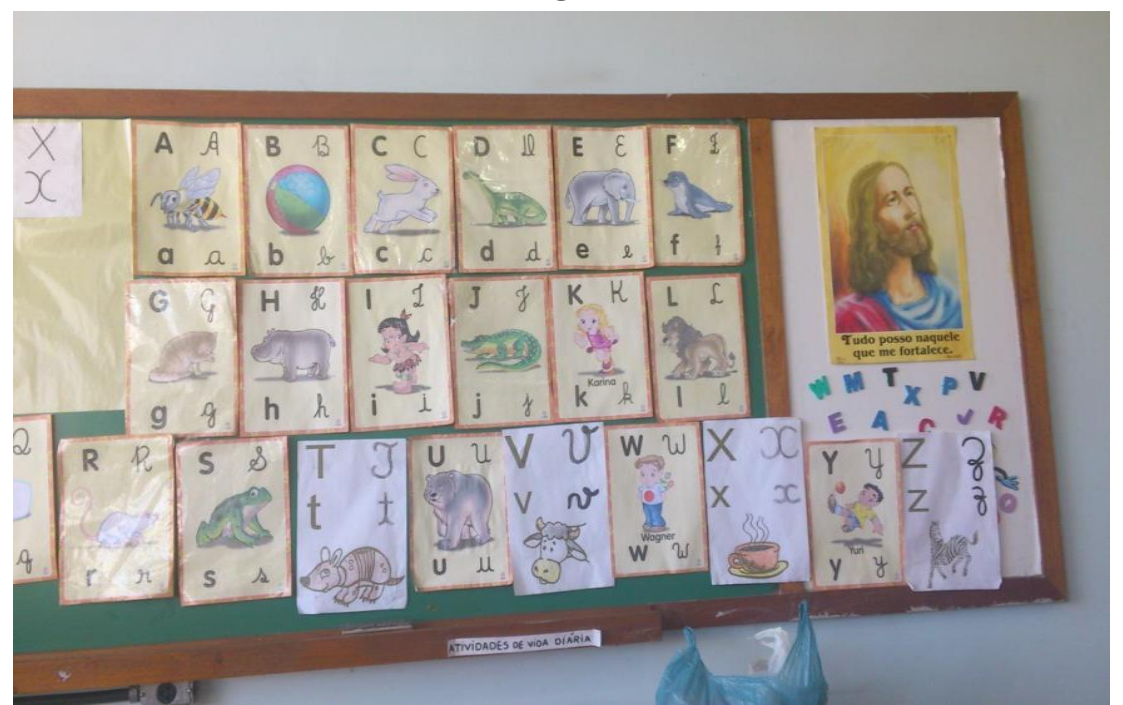

Fuente: Acervo do Projeto "Narrar las experiencias de alteridad en Educación”- Lugar: una escuela de la ciudad de São Gonçalo, RJ, Brasil. Noviembre de 2009

Texto Imagen 4 - escrito por una de las estudiantes "normalidad-anormalidad...”

¿Será que una imagen vale más que mil palabras como oímos decir muchas veces? Con certeza ésta es una de las afirmaciones que valen más por el efecto que producen que por sus condiciones heurísticas.

Sin valer más que mil palabras -ya que unas y otras, palabras y cosas - son irreductibles unas a las otras como nos recuerda Foucault (2000), esta fotografía nos causó bastante inquietud por su posibilidad evocativa, por sus posibilidades de conectarse con las memorias afectivas de los estudiantes que participaron de la experiencia. Memorias llenas de procesos de naturalización, de normalización de determinados elementos, principalmente relacionados a diversas prácticas "alfabetizadoras" (tanto el abecedario reproducido como la imagen cristiana) Hemos repetido, muchas veces, "esto es normal, una simple cartelera en cualquier escuela" produciendo una didáctica de la mirada.

La fotografía de esta escena pone en evidencia como fuerte dispositivo de visibilidad y enunciación por un lado, aquello que se naturaliza como siendo el sentido legítimo de la existencia de la escuela -el aprendizaje de los códigos alfabéticos- y por otro, la fuerte presencia del cristianismo -aquí a través de una imagen- como marca natural de los espacios públicos. La estudiante produce y trae al interior de la discusión una imagen que transformamos en pista para pensar la producción de normas y procesos de naturalización en 


\section{pro.posições}

$e-I S S N$ 1980-6248

http://dx.doi.org/10.1590/1980-6248-2017-0036

las instituciones escolares. Apostamos, como decimos en la página tres de este texto -junto con Carlos Skliar- en producir una mirada menos vigilante pero atenta no ya, a lo que se produce como anormalidad (por ejemplo, no hay fotografías de alumnos de la escuela, las llamadas personas con deficiencias) sino en problematizar radicalmente el poder de la normalidad y de la naturalización, haciéndolas problema.

Al mirar nuestras prácticas pedagógicas, nos preguntamos si estas no estarían tomadas de informaciones que sólo exigen a los estudiantes la retención de cosas muertas que no consiguen implicarse con sus vidas. En este punto queremos acentuar dos cuestiones, suponiendo que algunos de nosotros ya trabajamos con narrativas textuales e imagéticas como punto de articulación de nuestras prácticas pedagógicas, de nuestras investigaciones: ¿Será que lo que llamamos narrativa, de relatos no están siendo, primero, descuidados en su condición de trama de organización de la experiencia en el tiempo, como posibilidad de reconfiguración del tiempo humano? ¿Será que estas narrativas no están siendo tratadas sólo como información literal, o será que no estamos exigiendo de ellas lo que exigimos de la información - que nos digan la verdad - para ser transformadas en datos y ejemplos empíricos - que nos ofrezcan un terreno seguro para que podamos, a partir de allí, fundar nuestras enunciaciones (que siempre se hacen sobre terrenos arenosos, pantanosos, etc.)?

Como apuesta a la problematización de esta forma escolar y desde la pregunta sobre cómo "Narrar las experiencias de alteridad en Educación", trabajamos desde un ejercicio didáctico de problematización sobre las formas de mostrar y mirar las diferencias en educación, especialmente a partir de fotografías producidas por los propios alumnos en la práctica pedagógica que desarrollan en escuelas. Algunas cuestiones acompañaron las actividades, cuestiones que fueron consideradas a lo largo del texto: ¿Dónde cada uno se puso para mirar? ¿Cuáles fueron los desplazamientos posibles? o sea, ¿Cómo se dieron y produjeron las búsquedas de otras posibilidades de mirar? ¿Qué fue posible mirar? ¿Qué y cómo se comportó el cuerpo y la mirada frente a los otros? ¿ De qué manera escogimos lo que miraríamos y de lo que desviaríamos la mirada? Insistentemente los aportes de las estudiantes iban desde aquello que uno puede (o no puede) con su mirada: coincidieron en el esfuerzo realizado para poder salir de un discurso y de una mirada que traían como acabada. Esfuerzo materializado en la incomodidad de salirse del lugar formativo ya ocupado con tranquilidad. Destacaron lo que fue posible de ser pensado desde la producción de imágenes como otra posibilidad narrativa, principalmente las aperturas para la movilización de otros 


\section{pro.posıções}

$e-I S S N$ 1980-6248

http://dx.doi.org/10.1590/1980-6248-2017-0036

saberes, otras sensibilidades y ampliación de los conocimientos. También, el verse en el propio acto de mirar al otro, al mirar la escuela y extrañarla y descubrirla como desconocida. La problematización de aquello que suponemos ser lo real. Hablaron de la posibilidad de dar a ver (como relato imagético o verbal) no sólo la confirmación del consenso sobre el mundo, sino también, la producción de una mirada otra, tal vez más frágil, más singular, más dubitativa pero, al mismo tiempo, más encarnada y productora de caminos formativos diversos.

Tal vez podamos pensar, en nuestras prácticas pedagógicas o en las actividades de investigación sobre la necesidad de problematizar la formación de profesores desde un dominio únicamente instrumental, desde un dominio que impone sólo la técnica y aparta los sujetos de la educación y sus experiencias, sus historias, sus implicaciones con el mundo. Problematizar y desnaturalizar una formación que, desde una determinada racionalidad ya tiene definido lo que se debe saber como posibilidad de anticipación del mundo: formación como lugar de la suspensión de la experiencia y el reinado de la información actualizada, lugar del abandono de los cuerpos y de sus marcas.

Lo que intentamos, con la experiencia didáctica relatada, fue mostrar los efectos de ejercicios de desterritorialización, de situarnos en las escenas para pensar los encuentros, los acontecimientos, y, colocar el cuerpo como territorio de pasaje de la experiencia didáctica. Pensar la normalidad y la anormalización como producciones de didácticas de la mirada que interfieren en la percepción y en la acción pedagógica. Lo que pretendimos fue la creación de un espacio-tiempo para el pensamiento de cuestiones sobre nuestra relación con el otro, nuestra relación con el mundo enunciado como alteridad utilizando metáforas de la fotografía y de la producción imagética.

Pretendimos, pues, forzar un ejercicio de pensamiento sobre las prácticas pedagógicas y las didácticas de la mirada, sobre la producción del conocimiento a partir de la comprensión de que la producción de sí y del otro dependen, también de aquello que creamos a través de nuestras miradas. 


\section{pro.posıções}

$e$-ISSN 1980-6248

http://dx.doi.org/10.1590/1980-6248-2017-0036

\section{Referencias}

Barros, M. (2000). Ensaios fotográficos. Rio de Janeiro: Record.

Benjamin, W. (1994). Magia e técnica, arte e política. São Paulo: Brasiliense.

Bergson, H. (1990). Matéria e memória. São Paulo: Martins Fontes.

Candau, V., \& Lellis, I. (1999). A relação teoria-prática na formação do educador. In V. Candau (Org.), Rumo a uma nova Didática (pp.56-72). Petrópolis: Vozes.

Climaço, J. C. (2010). Discursos jurídicos e pedagógicos sobre a diferença na Educação especial. Buenos Aires: Flacso.

Foucault, M. (2000). As palavras e as coisas. São Paulo: Martins Fontes.

Gadamer, H. (1977). Verdady Método. Salamanca: Sígueme.

Gutiérrez, D. (2006). El eros pedagógico. In J. Larrosa, \& C. Skliar, Entre pedagogía y literatura (pp. 165-187). Buenos Aires, Argentina: Miño y Dávila.

Larrosa, J. (2001). Notas sobre a experiência e o saber de experiência. Medio Digital. Palestra en 13. COLE-Congresso de Leitura do Brasil (2001), realizado en UNICAMP/ SP. $\begin{array}{llllll}\text { Recuperado el de } & 7 \text { noviembre de 2016, }\end{array}$ http://www.scielo.br/pdf/rbedu/n19/n19a02.pdf

Larrosa, J. (2006a). Niños atravesando el paisaje. In J. Larrosa, Educar la mirada: politicas y pedagogías de la imagen (pp.113-135). Buenos Aires: Manantial.

Larrosa, J. (2006b). Una lengua para la conversación. In J. Larrosa, \& Skliar, C. (Orgs.), Entre Pedagogía y Literatura (pp. 25-41). Buenos Aires: Miño y Dávila.

Ministério da Educação [MEC] (2008). Política Nacional de Educação Especial na Perspectiva da Educação Inclusiva. Recuperado el 7 de noveiembre de 2016, de http://portal.mec.gov.br/seesp/arquivos/pdf/politica.pdf

Pérez de Lara, N. (2009). Escuchar el otro dentro de sí. In C. Skliar, \& J. Larrosa. Experiencia y alteridad en educación (pp.45-79). Buenos Aires: Homo Sapiens Ediciones.

Pérez de Lara, N., \& Contreras, J. (2010). Investigar la experiencia educativa. Madri: Morata.

Ricoeur, P. (2010). Tempo e narrativa (Vol. III). São Paulo: WMF Martins Fontes. 


\section{pro.posıções}

http://dx.doi.org/10.1590/1980-6248-2017-0036

$e$-ISSN 1980-6248

Skliar, C. (2005). Poner en tela de juicio la normalidad, no la anormalidad. Políticas y falta de políticas en relación con las diferencias en educación. Educación y Pedagogía, XVH(41), 41. Recuperado el 23 de octubre de 2016, de http://aprendeenlinea.udea.edu.co/revistas/index.php/revistaeyp/article/viewFile/60 $24 / 5431$

Skliar, C. (2009, Julio). Educar la mirada. Entrevista. Revista "Sin puntero" (n.3). (S. Kipersain, Dir., C. A. Tolosa, Ed.). Recuperado el 13 de noviembre de 2012, de http://laescuelaylosjovenes.blogspot.com.br/2010/02/educar-la-mirada.html

Skliar, C., \& Téllez, M. (2008). Conmover la Educación. Buenos Aires: Noveduc.

\section{Filmes}

Adler, K., Villar, L., Cezar, P., \& Treuffar, R. (Produtores), \& Cezar, P. (Direção). (2008). Só dez por cento é mentira: a desbiografia oficial de Manoel de Barros.

Tambellini F. R., \& Jardim, J. (Produtores), \& Jardim, J., \& Carvalho, W. (Diretores). (2001). Janela da Alma.

\section{Legislación}

Lei BR n. 9.394, de 20 de dezembro de 1996. (1996, 23 de dezembro). Estabelece as Diretrizes e Bases da Educação Nacional. Diário Oficial da União, seção 1, ano CXXXIV, n. 248.

Sometido a evaluación el 1 de marzo de 2017; revisado el 27 de junio de 2017; acepto para publicación el 17 de julio de 2017. 